\title{
Kajian Awal Kontaminasi Pestisida Organoklorin dalam Air Laut di Wilayah Perairan Paling Barat Semarang
}

\author{
Chrisna Adhi Suryono ${ }^{*}$, Baskoro Rochaddi ${ }^{2}$ Irwani $^{1}$ \\ ${ }^{1}$ Departemen Ilmu Kelautan, ${ }^{2}$ Departemen Oseanografi \\ Fakultas Perikanan dan Ilmu Kelautan Universitas Diponegoro, Semarang \\ Kampus Tembalang, Semarang 50275 Telp/Fax. 024-7474698 \\ Email : chrisna_as@yahoo.com
}

\begin{abstract}
Abstrak
Hasil penelitian menunjukkan bahwa air laut dari wilayah perairan paling barat Semarang telah terkontaminasi pestisida organoklorin. Hasil tersebut menunjukkan bahwa konsentrasi yang tinggi ditemukan pada beberapa pestisida seperti Heptachlor, Aldrin, Endosulfan, Endrin, dan pp-DDT dengan nilai kisaran sebesar $0.319 \pm 0.231,0.227 \pm 0.093,0.119 \pm 0.080,1.023 \pm 0.553,0.906 \pm 0.005 \mathrm{ppb}$. Bila dibandingkan dengan baku mutu dari Kementerian Lingkungan Hidup untuk kehidupan organisme laut dan wisata masih diketegorikan tinggi dan terkontaminasi pestisida organoklorin.
\end{abstract}

Kata Kunci : órgano klorin, kontaminasi, Semarang

\begin{abstract}
The present study was conducted to assess the level of organochlorine contamination in marine sea water in western part of Semarang. The results showed that Heptachlor had highest value among organochlorine pesticides (0.319 \pm 0.231$)$ followed by Aldrin (0.227 \pm 0.093$)$, Endosulfan $(0.119 \pm 0.080)$, Endrin (1.023 \pm 0.553$)$, and pp-DDT $(0.906 \pm 0.005) \mathrm{ppb}$, respectively. Comparison of the organochlorine contents in the water samples with the standard quality of marine water for marine organism and recreation from Indonesian Environmental Bureau $(K L H)$ showed that all of the marine water samples were contaminated with organochlorine pesticide
\end{abstract}

Keywords: organochlorine, contaminated, Semarang

\section{PENDAHULUAN}

Penggunaan pestisida, herbisida, dan fungisida di Indonesia secara intensif dimulai pada tahun 1960-an saat dimulainya intensifikasi pertanian (Indonesian Pesticide Committee, 1999 dalam Sabdono et al, 2008). Program intensifikasi pertanian terutama padi dengan menggunakan pestisida tidak hanya di Indonesia namun juga terjadi di seluruh Asia (Carvalho 2006; Sattler et al. 2007; Cooper \& Dobson 2007). Dampak penggunaan pestisida pada pertanian padi terutama pada sawah dataran rendah akan mencemari lingkungan perairan sekitar (Miao et al. 2003). Hal tersebut juga terjadi pada lahan padi di pesisir Pulau Jawa seperti Semarang dimana banyak lahan padi dataran rendah yang memiliki saluran menuju ke laut. Karena salah satu cara masuknya kontaminan pestisida ke laut adalah melalui aliran sungai.
Dampak dari penggunaan secara meluas racun tersebut dalam pertanian adalah ditemukannya material tersebut dalam berbagai sistem seperti dalam air permukaan, air bawah tanah, danau, sungai, estuaria, maupun perairan laut. Tahun 1974 dikeluarkan secara resmi daftar 94 jenis pestisida, yang merupakan representasi dari 76 jenis material pestisida. Beberapa jenis pestisida di pasaran memiliki nama dagang yang berbeda (Hadiwijaya, 1974). Tidak termasuk didalamnya adalah dari turunan DDT, Endosulfan, Heptachlor, Aldrin, Dieldrin, Endrin dan beberapa jenis pestisida organoklorin yang persistent. Kesemuanya itu di gunakan dalam pertanian dan perkebunan (Duursma, 1974). Meskipun saat ini DDT masih digunakan dalam rumah tangga dan pemeliharaan kesehatan masyarakat terutama dalam pembasmian nyamuk malaria. Dieldrin dan Endrin masih digunakan secara luas dan di
*) Corresponding author

buloma.undip@gmail.com http://ejournal.undip.ac.id/index.php/buloma

Diterima/Received : 11-05-2016

Disetujui/Accepted : 22-07-2016 


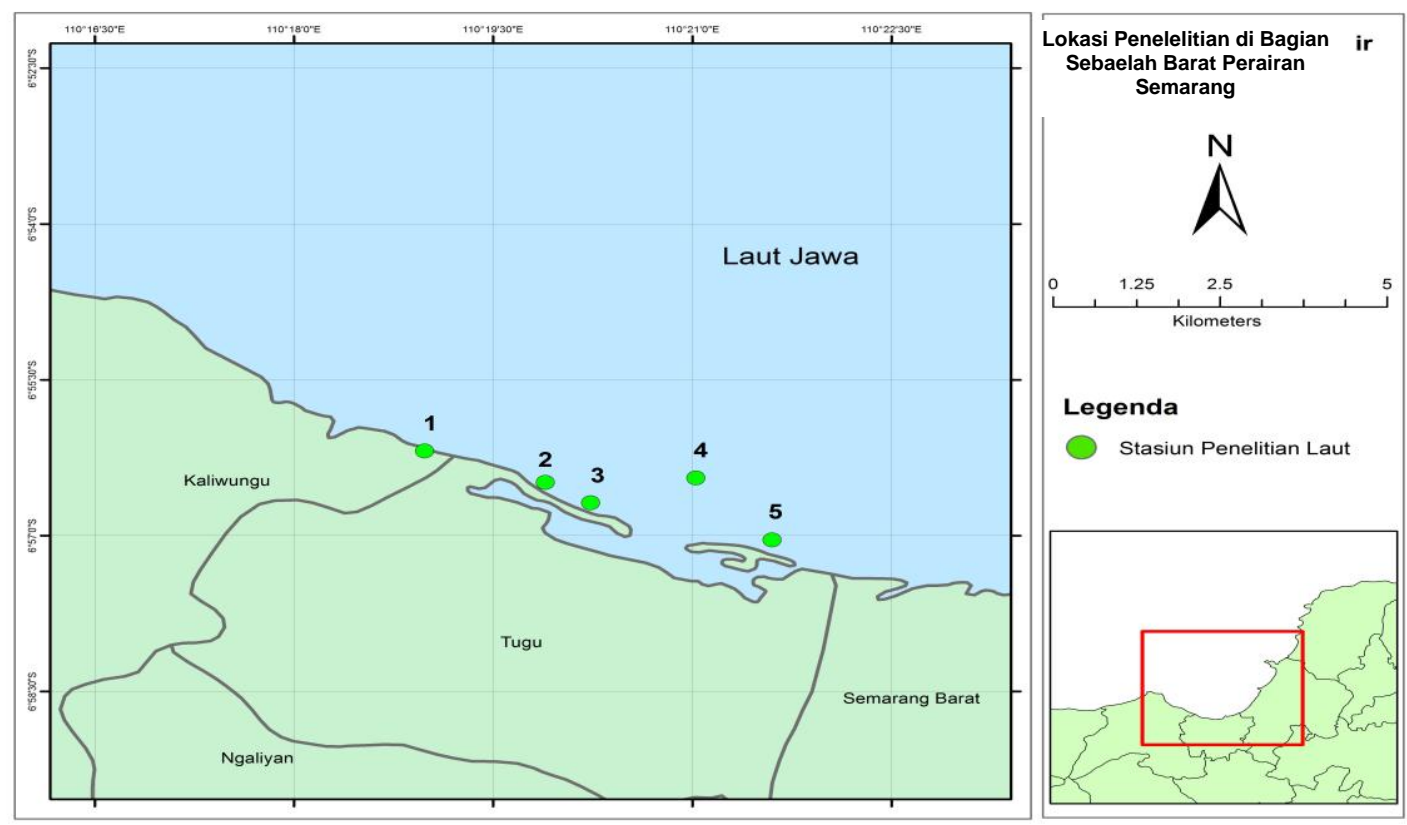

Gambar 1. Lokasi penelitian di wilayah perairan laut bagian barat Semarang

beberapa daerah ketersedianya masih ada, hal ini yang menyebabkan kemungkinan ditemukanya dalam lingkungan (Chozanah, 2007 \& Watterson, 1999). Beberapa kasus telah terjadi di Jepang dimana pestisida yang digunakan dalam pertanian padi telah megkontaminasi lingkungan sekitarnya seperti sungai dan danau (Numabe and Nagahora 2006; Kawakami et al. 2005).

Namun sampai sekarang belum diketahui adanya kemungkinan pestisida mencemari lingkungan pesisir dan laut yang dihasilkan dari sawah padi. Karena normalnya pestisida tersebut akan mengalami perjalanan panjang sebelum sampai di wilayah pesisir (Anasco, et al. 2010). Hampir keseluruhan residu pestisida akan mengalami penguraian secara physicochemical dan factor-faktor biologis selama perjalanannya masuk ke lingkungan.

Namun ini merupakan kasus yang ada di Jepang di mana sawah padi ada di daerah upstream (hulu). Namun di pesisir pantai utara Pulau Jawa sawah padi sangat luas dan kebanyakan masih berbatasan dengan wilayah pesisir seperti yang ada di Semarang. Di wilayah Semarang bagian barat dimana wilayah pesisir daratanya masih banyak terdapat sawah padi dan tambak yang masih menggunakan pestisida untuk membasmi hama dan masukan air sungai yang hulunya merupakan perkebunan seperti di daerah Boja. Maka dari itu kajian tentang pestisida organoklorin di dalam air laut terutama di perairan Semarang bagian barat perlu di lakukan.

\section{MATERI DAN METODE}

Materi yang digunakan dalam penelitian ini adalah air laut yang diambil di perairan laut Semarang bagian barat antara Kabupaten Kendal dan Kecamatan Semarang Barat. Sampel air diambil di lima stasiun mengikuti penelitian penggambilan sampel logam berat dalam sedimen sebelumnya (Suryono, 2016). Ulangan dilakukan sebanyak empat kali dalam selang satu mingguan. Sampel diambil dengan munggunakan botol sampel volume 3 liter yang sebelumnya telah dibersihkan dengan acetone kemudian sebelum dianalisa sampel disimpan dalam suhu $4^{\circ} \mathrm{C}$ (Anasco et al., 2010).

Sampel dianalisa menggunakan prosedur Standard Method for the Examination of Water and Waste Water (American Public Health Association, 1992), dengan menggunakan 15\% methylene chloide dalam n-hexane dan kolom kapilar. Satu liter sampel diekstrak dengan larutan campuran dan kemudian dipekatkan dalam apparatus Kudena Danish. Kemudian ekstrak dibersihkan dengan kolom Florisil. Hasil ektrak pestisida adalah $5 \mathrm{ml}$ dalam hexane. Sampel kemudian dianalisa dalam gas chromatografi Model Hitachi 163 FPD (Flame Photometer Detector) dan nitrogen High Pure (HP) sebagai gas carrier.

\section{HASIL DAN PEMBAHASAN}

Hasil pengamatan terhadap pestisida organoklorin dalam air laut di Wilayah Perairan 
Paling Barat Semarang menunjukan hasil seperti yang terdapat pada tabel 1 dan 2. Hasil analisa menunjukan bahwa semua jenis pestisida dari golongan organoklorin seperti Heptachlor, Aldrin, Endosulfan, Endrin, dan pp- DDT ditemukan di peraian tersebut. Konsentrasi rata rata pestisida tersebut lebih tinggi dari standar baku mutu untuk syarat organisme laut hidup maupun kepentingan pariwisata. Konsentrasi rata rata paling tinggi terdapat pada Endrin $(1.023 \pm 0.553 \mathrm{ppb})$ dan paling rendah Endosulfan $(0.119 \pm 0.080 \quad$ ppb). Meskipun konsentrasi Endosulfan yang paling rendah namun konsetrasi tersebut masih sepuluh kali lipat standar baku mutu organisme laut.
Heptachor merupakan pestisida yang ditemukan pada semua stasiun pengangatan dengan rangan antara 0,12 - 0,74 ppb sedangkan Endrin (0,502$1,55 \mathrm{ppb})$ dan pp DDT $(0,899-0,911 \mathrm{ppb})$ hanya ditemukan pada stasiun 3. Stasiun tiga merupakan daerah paling banyak ditemukan pestisida seperti Heptachor (0.14 \pm 0.023$)$, Endosulfan (0.045 \pm $0.002)$, Endrin $(0.51 \pm 0.003)$ dan pp DDT $(0.91 \pm$ 0.005) kemudian diikuti oleh stasiun satu dan empat ditemukan pestisida seperti Heptachor $(0.72 \pm 0.009)$, Aldrin $(0.31 \pm 0.005)$ dan Endrin (1.54 \pm 0.008). Pada stasiun empat juga ditemukan tiga pestisida seperti Heptachor (0.399 \pm 0.034$)$, Aldrin $(0.14 \pm 0.007)$, Endosulfan $(0.194 \pm 0.003)$. Stasiun dua dan lima hanya

Tabel 1. Frekuensi, kisaran, rata rata $\pm \mathrm{SD}$, standar baku mutu untuk biota dan wisata pestisida organoklorin di bagian paling barat Semarang

\begin{tabular}{|c|c|c|c|c|c|}
\hline \multirow{2}{*}{ Stasiun } & \multicolumn{5}{|c|}{ Pestisida (ppb) } \\
\hline & Heptachor & Aldrin & Endosulfan & Endrin & pp DDT \\
\hline \multirow[t]{4}{*}{1} & 0.713 & 0.308 & $b d$ & 1.54 & $b d$ \\
\hline & 0.721 & 0.316 & $b d$ & 1.53 & $b d$ \\
\hline & 0.726 & 0.315 & $b d$ & 1.54 & $b d$ \\
\hline & 0.735 & 0.319 & $b d$ & 1.55 & $b d$ \\
\hline \multirow[t]{4}{*}{2} & 0.208 & $b d$ & $b d$ & bd & $b d$ \\
\hline & 0.213 & $b d$ & $b d$ & bd & $b d$ \\
\hline & 0.216 & $b d$ & $b d$ & bd & $b d$ \\
\hline & 0.218 & $b d$ & $b d$ & bd & $b d$ \\
\hline \multirow[t]{4}{*}{3} & 0.126 & $b d$ & 0.043 & 0.502 & 0.899 \\
\hline & 0.12 & $b d$ & 0.044 & 0.505 & 0.908 \\
\hline & 0.145 & $b d$ & 0.047 & 0.507 & 0.905 \\
\hline & 0.17 & $b d$ & 0.045 & 0.509 & 0.911 \\
\hline \multirow[t]{4}{*}{4} & 0.351 & 0.135 & 0.189 & $b d$ & $b d$ \\
\hline & 0.397 & 0.135 & 0.195 & $b d$ & $b d$ \\
\hline & 0.421 & 0.14 & 0.194 & $b d$ & $b d$ \\
\hline & 0.426 & 0.15 & 0.196 & $b d$ & $b d$ \\
\hline \multirow[t]{4}{*}{5} & 0.119 & $b d$ & $b d$ & $b d$ & $b d$ \\
\hline & 0.121 & $b d$ & $b d$ & $b d$ & $b d$ \\
\hline & 0.12 & $b d$ & $b d$ & $b d$ & $b d$ \\
\hline & 0.122 & $b d$ & $b d$ & $b d$ & $b d$ \\
\hline$\%$ kehadiran & 100 & 40 & 40 & 40 & 20 \\
\hline Kisaran & $0,12-0,74$ & $0,135-0,319$ & $0,043-0,196$ & $0,502-1,55$ & $0,899-0,911$ \\
\hline Rata-rata $\pm \mathrm{SD}$ & $0.319 \pm 0.231$ & $0.227 \pm 0.093$ & $0.119 \pm 0.080$ & $1.023 \pm 0.553$ & $0.906 \pm 0.005$ \\
\hline sbm Biota & 0,01 & 0,01 & 0,01 & 0,01 & 0,01 \\
\hline$s b m$ Wisata & nihil & nihil & nihil & nihil & nihil \\
\hline
\end{tabular}


ditemukan Heptachor (Tabel 2 dan Gambar 2). Konsentrasi pestisida organoklorin paling tinggi terdapat pada Endrin kemudian diikuti oleh pp DDT dan Heptachor (Gambar 2).

Pestisida organoklorin merupakan persistent organic pollutants (POPs) yang memiliki sifat biodegradasi yang lambat dan mempunyai mobilitas dalam lingkungan biotik maupun abiotik (Wania and Mackay 1996; Rodanet et al., 1999). Menyikapi dampak terhadap makluk hidup, keberadaan di atmosfir yang lama, penyebaran secara global dan membeku di daerah dingin maka secara internasional POPs dilarang untuk diproduksi dan dipergunakan (Rodanet et al.1999). Selama beberapa dekade kontaminasi POPs seperti PCB dan DDT telah menyebar ke seluruh dunia ditemukan semua lingkungan dan biota (Tanabe, 2000). Meskipun semua negara maju telah

Tabel 2. Rata rata \pm SD dan frekuensi terukurnya pestisida organoklorin di Wilayah Perairan Paling Barat Semarang

\begin{tabular}{lccccc}
\hline \multirow{2}{*}{ Pestisida $(\mathrm{ppb})$} & \multicolumn{5}{c}{ Stasiun Sampling } \\
\cline { 2 - 6 } & Stasiun 1 & Stasiun 2 & Stasiun 3 & Stasiun 4 & Stasiun 5 \\
\hline \multirow{2}{*}{ Heptachor } & $0.72 \pm 0.009$ & $0.214 \pm 0.004$ & $0.14 \pm 0.023$ & $0.399 \pm 0.034$ & $0.121 \pm 0.001$ \\
& $4 / 4$ & $4 / 4$ & $4 / 4$ & $4 / 4$ & $4 / 4$ \\
Aldrin & $0.31 \pm 0.005$ & bd & bd & $0.14 \pm 0.007$ & bd \\
& $4 / 4$ & bd & bd & $4 / 4$ & bd \\
Endosulfan & bd & bd & $0.045 \pm 0.002$ & $0.194 \pm 0.003$ & bd \\
\multirow{2}{*}{ Endrin } & bd & bd & $4 / 4$ & $4 / 4$ & bd \\
& $1.54 \pm 0.008$ & bd & $0.51 \pm 0.003$ & bd & bd \\
pp DDT & $4 / 4$ & bd & $4 / 4$ & bd & bd \\
& bd & bd & $0.91 \pm 0.005$ & bd & bd \\
\hline
\end{tabular}

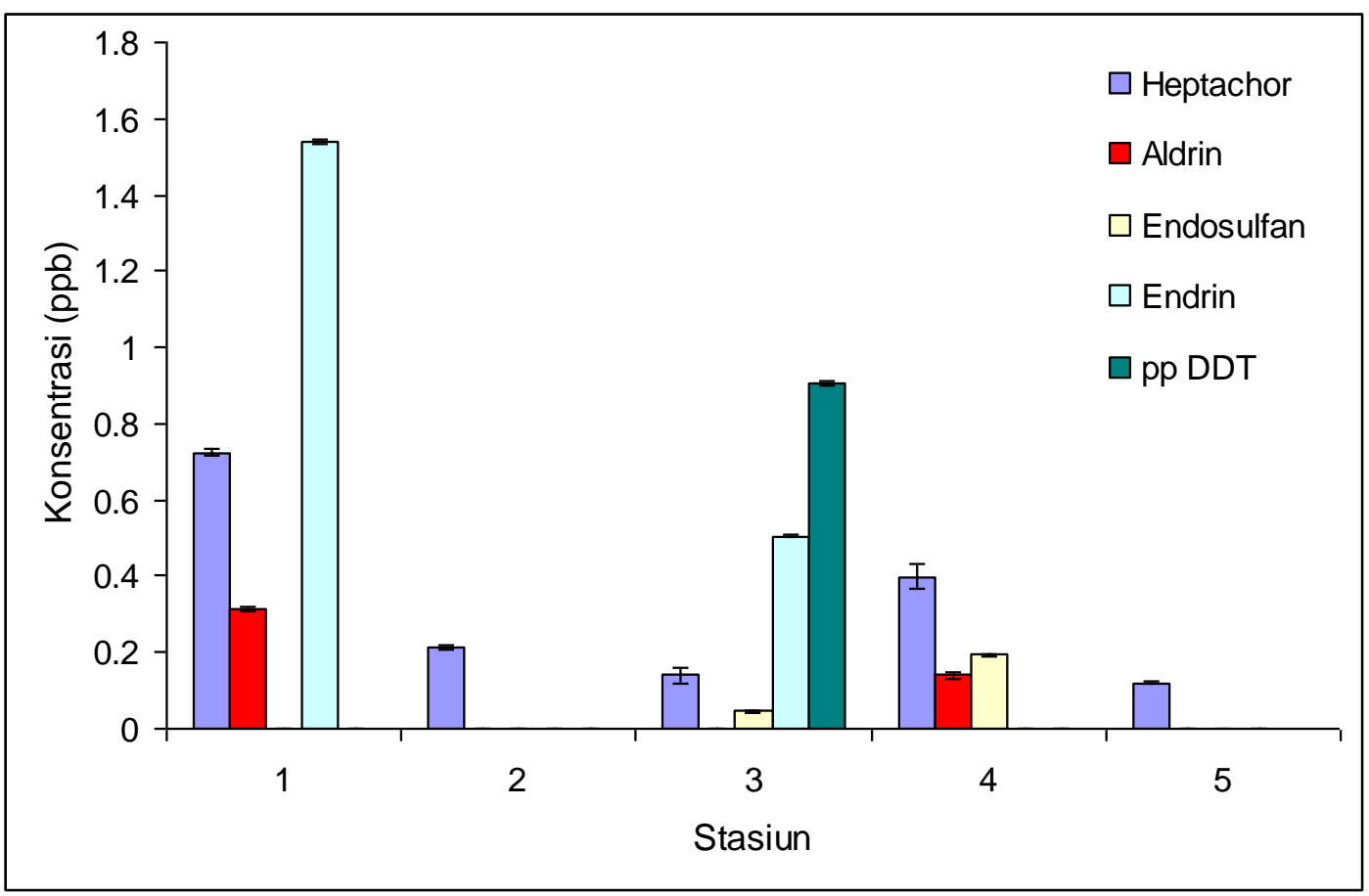

Gambar 2. Rata rata \pm SD kosentrasi pestisida organochlorine (Heptachlor, Aldrin, Endosulfan, Endrin, dan pp-DDT) di bagian paling barat Semarang 
melarang produksi dan penggunaan bahan tersebut sejak 1970-an namun beberapa negara kurang maju di Asia Pasifik masih menggunakan untuk kepentingan pertanian dan kesehatan (Dave 1996; Li et al., 1996). Hal inilah yang menjadi ketertarikan peneliti untuk mengetahui keberadaan pestisida organoklorin di perairan laut Semarang.

Hingga kini tidak tersedia data yang menunjukkan asal-usul bahan tersebut, apakah dari perkebunan, pertanian di hulu atau sawah dan tambak di sekitar pesisir Semarang. Pestisida umumnya berdampak yang lebih luas jika terlarut dalam air, sebab akan lebih mudah terpindahkan baik ke dalam sedimen biota maupun atmosfir. Diduga organochlorin pestisida persiten yang ada di Semarang telah mengkontaminasi lingkungan biotik maupun abiotik, hal tersebut terbukti di berbagai negara. Secara periodik pengambilan sampel kontaminan POP dalam mamalia laut menunjukkan penurunan pada daerah Barat Daya Samudera Atlantik, Laut Utara dan Laut Baltik (Aguilaret et al., 2002). Penurunan yang lambat bahkan berhenti pada beberapa jenis POPs telah ditemukan juga pada beberapa jenis mamalia perairan di daerah Asia Pasifik (Tanabet et al., 2003). Hal tersebut telah diusulkan bahwa laut memiliki peran akhir dalam sirkulasi dan pengendapan POPs di dasar laut (Tanabet et al., 1994). Maka dari itu monitoring POPs dalam ekosistem laut termasuk di perairan laut Semarang merupakan keharusan untuk kepentingan konservasi lingkungan dan kehidupan di masa akan datang.

\section{DAFTAR PUSTAKA}

Aguilar, A., Borrell, A., \& Reijnders, P.J.H., 2002., Geographical and temporal variation in levels of organochlorine contaminants in marine mammals. Mar Environ Res 53:425452

Anasco, N.C., Koyama, J, \& Uno, S., 2010. Pesticide residues in coastal waters affected by rice paddy effluents temporarily stored in a wastewater reservoir in Southern Japan. Arch. Environ. Contam. Toxicol. 58:352360. DOI 10.1007/s00244-009-9364-1

Carvalho, F.P. 2006. Agriculture, pesticides, food security and food safety. Environ. Sci. Policy. 9:685-692

Chozanah, M. 2007. Concentration of organochlorine pesticide in NAD waters, post tsunami.
Cooper J., \& Dobson, H., 2007., The benefits of pesticides to mankind and the environment. Crop. Protect. 26:1337-1348

Dave, P.P., 1996., India: A generic giant. Farm. Chem. Int. 10:36-37

Duursma, E.K. 1976. Role of pollution and pesticides in brackishwater aquaculture in Indonesia., FAO Expert Pollution/Pesicides, Indonesia

Hadiwijaya, T. 1974. List of allowed pesticides in Indonesia. Lampiran Surat Keputusan Menteri Pertanian. No 582/Kpts/Um/1974

Kawakami, T., Ishizaka, M, \& Ishii, Y. 2005. Concentration and distribution of several pesticides applied to paddy fields in water and sediment, from Sugao Marsh, Japan. Bull. Enviro. Contam. Toxicol. 74:954-961

Keputusan Mentri Negara Lingkungan Hidup Nomor 51 Tahun 2004. Tentang Baku Mutu Air Laut

Li, Y., Mcmillan, A., \& Scholtz, M.T. 1996. Global $\mathrm{HCH}$ usage with $1^{\circ} \times 1^{\circ}$ longitude/latitude resolution. Environ. Sci. Technol. 30:3525-3533

Miao, Z., Padovani, L., Riparbelli, C., Ritter., A.M., Trevisan, M., \& Capri, E. 2003. Prediction of the environmental concentration of pesticide in paddy field and surrounding surface water bodies. Paddy Water Environ. 1:121-132

Numabe, A, \& Nagahora, S. 2006. Estimation of pesticide runoff from paddy fields to rural rivers. Water Sci. Technol. 53:139-146

Rodan, B.D., Pennington, D.W., Eckley, N., \& Boethling, R.S. 1999. Screening for persistent organic pollutants: Techniques to provide a scientific basis for POPs criteria in international negotiations. Environ. Sci. Technol. 33:3482-3488

Sabdono, A., Rochaddi, B., Chrisna, A.S, \& Susanti, B. 2008. Persistent organochlorine residues in household wells of Java central urban areas, Indonesia., J. App. Sci. 8(12): 2318-2323

Sattler, C., Kachele, H., \& Verch, G. 2007. Assessing the intensity of pesticide use in agriculture. Agric. Ecosyst. Environ. 119:299-304

Suryono, C.A. 2016. Polusi logam berat antropogenik (As, $\mathrm{Hg}, \mathrm{Cr}, \mathrm{Pb}, \mathrm{Cu}$ dan $\mathrm{Fe}$ ) pada Pesisir Kecamatan Tugu Kota Semarang Jawa Tengah. Jurnal Kelautan Tropis 19(1): 37-42 
Tanabe, S. 2000. Asian developing regions: Persistent organic pollutants in the seas. In: Sheppard CRC (ed) Seas at the millennium: An environmental evaluation. Elsevier Science, Amsterdam, pp 447-462

Tanabe, S., Iwata, H., \& Tatsukawa, R. 1994. Global contamination by persistent organochlorines and their ecotoxicological impact on marine mammals. Sci. Total Environ. 154:163-177

Tanabe, S., Niimi, S., Minh, T.B., Miyazaki, N., \& Petrov, E.A. 2003. Temporal trends of persistent organochlorine contamination in Russia: A case study of Baikal and Caspian seal. Arch. Environ. Contam. Toxicol. 44:533-545

Wania, F., \& Mackay, D. 1996. Tracking the distribution of persistent organic pollutants. Environ. Sci. Technol. 30:390A-396A

Watterson, A. 1999. Pesticides and reproduction: Wowen farmer in Indonesia. Pesticides News, 44:2-14 